Review Paper

\title{
A review on nanofluid: preparation, stability, thermophysical properties, heat transfer characteristics and application
}

\author{
Abu Raihan Ibna Ali ${ }^{1}\left[\right.$ ] Bodius Salam ${ }^{1}$
}

Received: 13 May 2020 / Accepted: 24 August 2020 / Published online: 5 September 2020

(c) Springer Nature Switzerland AG 2020

\begin{abstract}
Nanofluid is a suspension of nanoparticles which is promising heat transfer fluid in the heat transfer enhancement having a plethora of applications because of its superior thermal conductivity and rheological properties. This paper points out the previous studies and recent progress in the improvement of heat transfer using nanofluid. The recent progresses on preparation and enhancement of stability were reviewed. Thermophysical, heat transfer characteristics of nanofluid and different factors such as particle size, shape, surfactant, temperature, etc. on thermal conductivity were presented. The present study reveals potential applications by utilizing nanofluid such as heat exchanger, transportation cooling, refrigeration, electronic equipment cooling, transformer oil, industrial cooling, nuclear system, machining operation, solar energy and desalination, defense, etc. Few barriers and challenges were also addressed. Finally, the challenges and further research opportunities were presented.
\end{abstract}

Keywords Nanofluid $\cdot$ Preparation $\cdot$ Stability $\cdot$ Thermophysical properties · Application

\section{List of symbols}

W Weight

$C_{p} \quad$ Specific heat

$K \quad$ Thermal conductivity

T Temperature

$K_{B} \quad$ Boltzmann constant

$r_{c} \quad$ Apparent radius of clusters

$C_{f} \quad$ Heat capacity of the fluid per unit volume

$u_{p} \quad$ Brownian velocity of the nanoparticles

$\mathrm{Nu} \quad$ Nusselt number

Re Reynold number

\section{Greek symbol}

$\phi \quad$ Volume concentration

$\rho \quad$ Density

$\zeta \quad$ Zeta potential

$\psi \quad$ Sphericity

$\tau \quad$ Relaxation time

$\mu \quad$ Dynamic viscosity

\section{Subscripts \\ bf Base fluid \\ nf Nanofluid \\ np Nanoparticle}

\section{Abbreviations}

HTF Heat transfer fluid

MWCNT Multi wall carbon nanotube

CNT Carbon nanotube

EG Ethylene glycol

EO Engine oil

PVD Physical vapor deposition

EDLRF Electrical double layer repulsive force

ZSN Zeta sizer nano

TEM Transmission electron microscopy

SDBS Sodium dodecyl benzene sulfonate

SDS Sodium dodecyl sulphate

PVP Polyvinylprolidone

DTAB Dodecyltrimethylammonium bromide

OA Oleic acid

Abu Raihan Ibna Ali, abu.raihan.pilu@gmail.com; Bodius Salam, bsalam@cuet.ac.bd| 'Department of Mechanical Engineering, Chittagong University of Engineering \& Technology, Chittagong 4349, Bangladesh. 


$\begin{array}{ll}\text { EMT } & \text { Effective medium theory } \\ \text { VCRS } & \text { Vapour compression refrigeration system } \\ \text { PWR } & \text { Pressurized water reactors } \\ \text { ECCS } & \text { Emergency core cooling systems } \\ \text { CHF } & \text { Critical heat flux } \\ \text { DASC } & \text { Direct absorption solar collectors }\end{array}$

\section{Introduction}

Over decades, growing engineering disciplines are concerned with rapid heat transfer. Researchers are relentlessly working to enhance heat transfer rate, thermal conductivity and at the same time they are also trying to reduce frictional loss, pressure drop and pumping power for heat transfer fluid (HTF). A new type of HTF is engineered which provides improved thermal properties for heat transfer which is called as nanofluid. Nanofluid is prepared by suspending a small quantity of nanoparticles in base fluids such as water, ethylene glycol etc. with or without stabilization techniques. The average size of nanoparticles is below $100 \mathrm{~nm}$.

In 1981, Tuckerman familiarizes microchannel technology and after 12 years (in 1992), Argonne National Laboratory starts to work on nanofluid and later in 1993 Choi and Eastman termed these as "Nano fluid". In 1999, Lee et al. [1] investigated thermal conductivity of oxide nanoparticles dispersed in base fluid. Eastman et al. [2] found increase in thermal conductivity of ethylene glycol based nanofluids containing copper nanoparticles. Choi et al. [3] investigated thermal conductivity of nanotube suspension. In 2007, Das et al. [4] wrote the first book on nanofluids titled as "Nanofluids: Science and Technology" published by Wiley. Choi [5] suggested to use nanofluid in automotive cooling system. Twelve European companies and research centers launched world's largest research project ( $€ 8.3$ million) on the application of nanofluid titled as NanoHex [6].

Additional heat is one of the common challenges in different industries, manufacturing, heavy duties engine and machines, electronic devices etc. Traditional HTF has some limitations. Nanofluid overcomes some of these limitations by improving thermophysical properties. Because of enhanced thermophysical properties, nanofluids have potential applications in automobile engine coolant, cooling of high heat flux devices, coolant in electric generator, transformer etc. But Nanofluid developments are still impaired by a range of factors such as stability, lack of good theoretical model and mechanism understanding, production complexity, high production cost etc. In this regard, a comprehensive review of nanofluid research will enable researchers to understand the current research gap and recent developments of nanofluid which is the main objective of this paper.
Incorporation of nanoparticles dramatically improves the thermophysical properties of traditional heat transfer fluid which increase the heat transfer coefficient. These thermophysical properties are density, specific heat, thermal conductivity, and dynamic viscosity. The degree of enhancement of heat transfer depends on quantity of nanoparticles which is suspended in the base fluid. Metal oxides $\left(\mathrm{Al}_{2} \mathrm{O}_{3}, \mathrm{CuO}, \mathrm{TiO}_{2}, \mathrm{ZnO}, \mathrm{MgO}\right.$, $\mathrm{SiC}$ etc.) are preferred as nanoparticles which have high thermal conductivity. Nitride ceramics (AIN, SiN), carbon ceramics ( $\mathrm{SiC}, \mathrm{TiC}$ ) are also used as nanoparticles. Commonly used base fluids are water $\left(\mathrm{H}_{2} \mathrm{O}\right)$, ethylene glycol (EG), engine oil (EO) etc. Table 1 demonstrates thermal conductivity of different types of nanoparticles.

Recently, Peyghambarzadeh et al. [15] investigated $\mathrm{Al}_{2} \mathrm{O}_{3}$ /water nanofluid in the car radiator and found $45 \%$ heat enhancement than pure water. Nguyen et al. [16] carried out experiment $\mathrm{Al}_{2} \mathrm{O}_{3} /$ water at $6.8 \%$ volume nanoparticle concentration in the radiator type heat exchanger and found $40 \%$ increase in heat transfer coefficient. Hwang et al. [17] demonstrated that $8 \%$ enhancement of heat transfer coefficient was attained for the $3 \%$ volume concentration of $\mathrm{Al}_{2} \mathrm{O}_{3}$ /water nanofluid. Chavda et al. [18] investigated friction factor $\mathrm{CuO} /$ water nanofluid on different pipe and found that friction factor increases when volume concentration of $\mathrm{CuO} /$ water nanofluid increases. The increase in effective thermal conductivity and the variations of other thermophysical properties contribute in the enhancement of heat transfer. Many researchers consider that the Brownian motion of nanoparticles is also responsible for the large amount of heat transfer. Xuan and Roetzel [19] suggested to include the Brownian motion in the velocity formulation. The thermal boundary layer decreases because of random motion of nanoparticles

Table 1 Thermal conductivity of different nanoparticles

\begin{tabular}{|c|c|c|}
\hline Nanoparticles & $\begin{array}{l}\text { Thermal conductivity } \\
\mathrm{W} /(\mathrm{m} \cdot \mathrm{K})\end{array}$ & $\begin{array}{l}\text { Refer- } \\
\text { ences }\end{array}$ \\
\hline Diamond & 3300 & [7] \\
\hline MWCNT & $2000-3000$ & {$[8]$} \\
\hline $\mathrm{SiC}$ & 490 & [9] \\
\hline $\mathrm{Ag}$ & 429 & [10] \\
\hline $\mathrm{Cu}$ & 398 & [11] \\
\hline $\mathrm{Au}$ & 315 & [11] \\
\hline $\mathrm{Al}$ & 247 & [11] \\
\hline Si & 148 & [7] \\
\hline $\mathrm{MgO}$ & 54.9 & {$[12]$} \\
\hline $\mathrm{Al}_{2} \mathrm{O}_{3}$ & 40.0 & [13] \\
\hline $\mathrm{CuO}$ & 32.9 & [7] \\
\hline $\mathrm{ZnO}$ & 29.0 & [14] \\
\hline $\mathrm{TiO}_{2}$ & 8.4 & [14] \\
\hline
\end{tabular}


within the base fluid [20]. Gupta et al. [21] concluded that percolation, Brownian motion, and micro level convection are liable in enhancement of heat transfer. Researchers also found better result with the incorporation of nanoparticles in energy storage design [22].

The present work focuses on existing knowledge and research gap of preparation, enhancing techniques of stability, thermophysical properties, heat transfer characteristics. Also, the potential application fields of nanofluid are discussed in this review paper. Finally, the challenges and future research scope of nanofluid are mentioned.

\section{Advantages of nanofluid}

Heat transfer improves much for the addition of a small volume fraction of nanoparticles. Researchers are still investigating the advantages of nanofluid and reasons behind this heat transfer enhancement. Many researchers concluded as follows [23-27].

- The effective thermal conductivity of the fluid is increased by the dispersed nanoparticles. Effective thermal conductivity is a function of nanoparticle volume fraction. It increases for the increase in volume fraction of nanoparticles.

- Interaction between base fluid \& nanoparticles increases because of increased specific surface area of particles.

- The dispersed nanoparticles create Brownian motions which increase interaction and collision between fluid and particles.

- The dispersed nanoparticles intensify the turbulence and mixing fluctuation.

- The pumping power is comparatively less than base fluid for equivalent heat transfer.

- Absorption of solar energy can be increased with the help of nanofluid.

- Stability is better than other colloid suspension.

\section{Preparation of nanofluid}

Nanofluids are prepared by dispersing nanoparticles in the base fluid. Good dispersion is prerequisite for the application of nanofluid. Hence surfactants are used sometimes which enhance the stability of nanofluids. Besides, surface modification of the dispersed particles and application of strong force on the clusters of the dispersed nanoparticles may increase the stability of nanofluids. There are two fundamental methods to prepare nanofluids which are onestep and two-step physical. Chemical process is another emerging technology in preparation of nanofluids. The percentage of volumetric concentration is calculated from the Eq. (1)

Volume concentration, $\phi=\left[\frac{\frac{W_{n p}}{\rho_{n p}}}{\frac{W_{n p}}{\rho_{n p}}+\frac{W_{b f}}{\rho_{b f}}}\right] \times 100$

where $W_{n p}$ is weight of nanoparticles, $W_{b f}$ is weight of base fluid, $\rho_{n p}$ is density of nanofluid, and $\rho_{b f}$ is density of the base fluid.

These processes are shortly discussed below.

\subsection{One-step method}

In this method, some processes are avoided like drying, storage, transportation, and dispersion of nanoparticles. Stable nanofluid is prepared by Physical Vapor Deposition (PVD) technique in which direct evaporation and condensation of nanoparticles are carried in the base fluid. Pure and uniform nanoparticles are produced by this method. Hence accumulation of nanoparticles is reduced. The main drawbacks of one- step method is that the residual reactants are left in the nanofluids and also the cost is high. Zhu et al. [28] prepared Cu nanofluid one-step method.

\subsection{Two-step method}

This is the most economic method for large scale preparation of nanofluid. In two-step method, the nanoparticles are obtained by different methods and then these nanoparticles are dispersed into the base liquid for the desired nanofluid. This production process is inexpensive and massive. The main drawback of two- step method is aggregation of nanoparticles. Because of instability, surfactant is used. This is the commercial method to prepare nanofluid. Most of the researchers prefer this method in preparation of nanofluid for research. Zhu et al. [29] used two step method to prepare $\mathrm{Al}_{2} \mathrm{O}_{3}$ /water nanofluid. Figure 1 demonstrates the two-step method.

\subsection{Stability of nanofluid}

Stability of nanofluid is important to get the same thermophysical properties. Stability of nanofluid is related to electrical double layer repulsive force and Van der Waals attractive force. Electrical Double Layer Repulsive Force (EDLRF) must be higher than the Vander Waals attractive forces to get stable nanofluid. Van der Waals attractive forces between nanoparticles causes to get clustered because of attraction forces. If this force is high, nanoparticles get separated from base fluid and these clustered nanoparticles settle down at the bottom of vessel because 

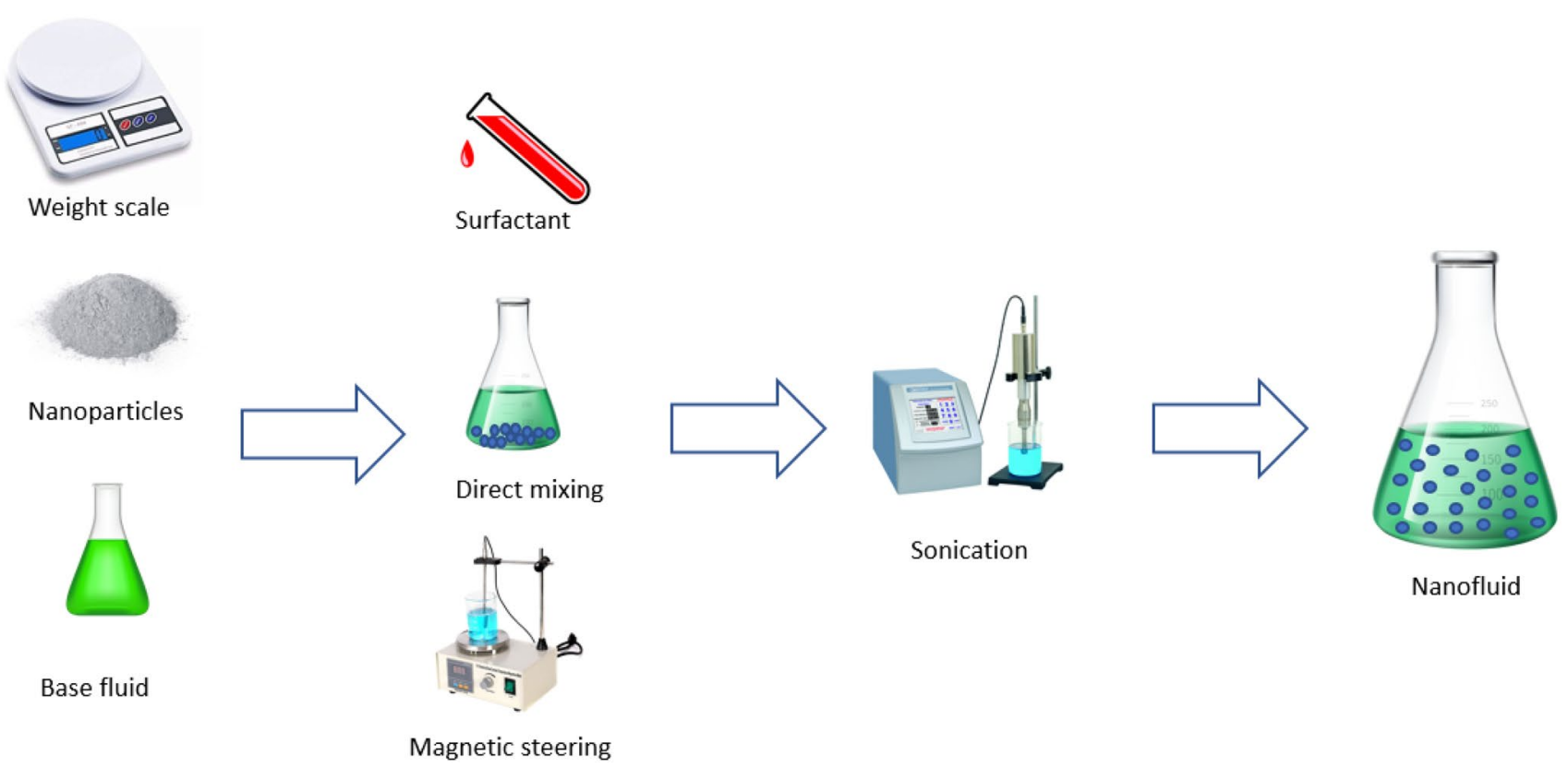

Fig. 1 Two step method

of gravitational force. On the other hand, EDLRF acts as opposite to Van der Waals attractive force which separates the particles from each other. Figure 2 demonstrates the sedimentation of $\mathrm{Al}_{2} \mathrm{O}_{3}$ nanoparticles without stabilizer at different time from the preparation of nanofluid.

\section{Evaluation of nanofluid stability}

Stability of nanofluid is important to get constant thermophysical properties. Researchers have been adopted different evaluation techniques to investigate the stability of nanofluid. Some common methods are described below.

\subsection{Sedimentation photograph method}

This method is also called photographic method. It is the simplest method which does not need sophisticated equipment. Particle settling is observed by relying on gravity. It is time consuming as nanofluid is observed for long time. In this method, pictures are captured by digital camera at equal intervals of time from the time of nanofluid preparation. To evaluate nanofluid stability, these pictures compared. It is called stable if there is no sedimentation occurs. Stability of $\mathrm{CuO}$ nanofluid was investigated by Sahooli et al. [30]. Other nanofluids including $\mathrm{Cu} /$ water $\&$ kaolinite/ water are also observed by some researchers using this method [31, 32].

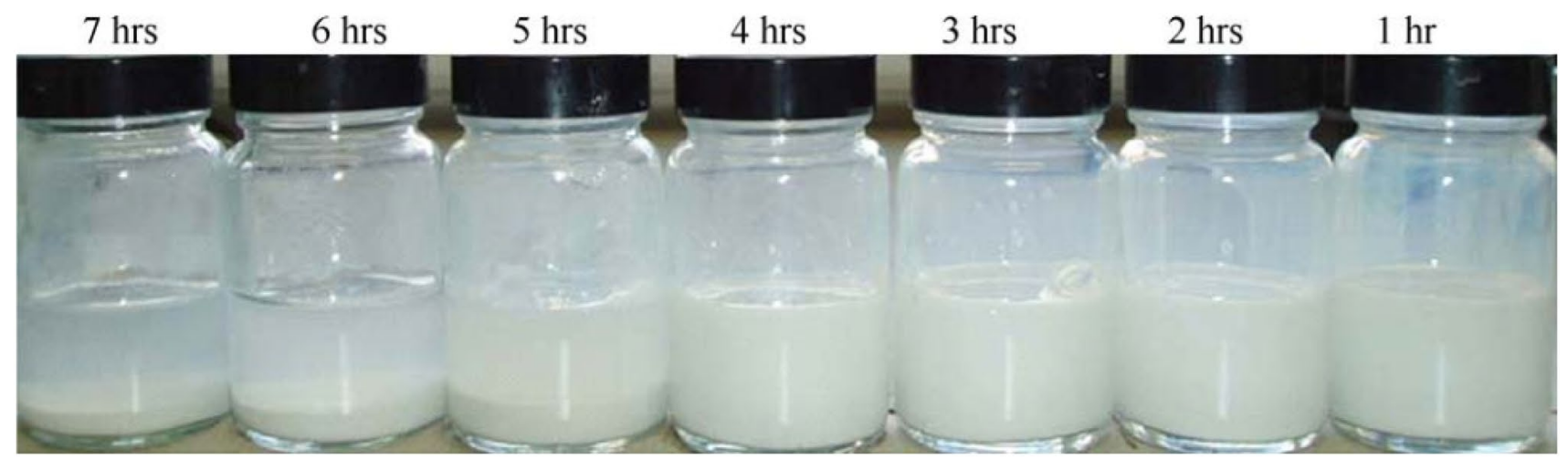

Fig. 2 Sedimentation of $\mathrm{Al}_{2} \mathrm{O}_{3}$ nanoparticles without stabilizer [23]

SN Applied Sciences 


\subsection{Centrifugation method}

Centrifugation method is the time saving method than sedimentation photograph method. Sedimentation takes place more rapidly as centrifugal force is higher than the gravity alone [33]. Mehrali et al. [34] examined the stability of graphene/distilled water by this method where dispersion analyzer centrifuge was used. Nanofluid was centrifuged at $6000 \mathrm{rpm}$ for a certain period such as 5 , 10 and $20 \mathrm{~min}$ in a plastic tube. The bottom of the tube is examined visually after the centrifugation. Their investigation gave satisfactory result in evaluating the stability of nanofluid at $6000 \mathrm{rpm}$ for $20 \mathrm{~min}$. Same method was also adopted by Singh and Raykar [35] in Ag/ethanol nanofluid. Sedimentation takes much time and high rpm in centrifugation method if the nanofluid is stable.

\subsection{Zeta potential}

Zeta potential is the potential difference between the stern layer of nanoparticle and base fluid. Generally, it is measured in millivolt. Zeta Sizer Nano (ZSN) is used to measure the value of zeta potential in which Smoluchowski equation is used to calculate zeta potential [36]. Short- and long-term stability of nanofluid can estimated from the value of Zeta potential. The stability of nanofluid

Table 2 Evaluation of nanofluid stability by Zeta potential [39]

\begin{tabular}{ll}
\hline Value zeta potential, $\zeta$ & Stability \\
\hline$\zeta> \pm 60 \mathrm{mV}$ & Excellent stability \\
$\pm 40 \mathrm{mV} \leq \zeta \leq \pm 60 \mathrm{mV}$ & Stable \\
$\zeta< \pm 30 \mathrm{mV}$ & Highly agglomerative \\
\hline
\end{tabular}

a

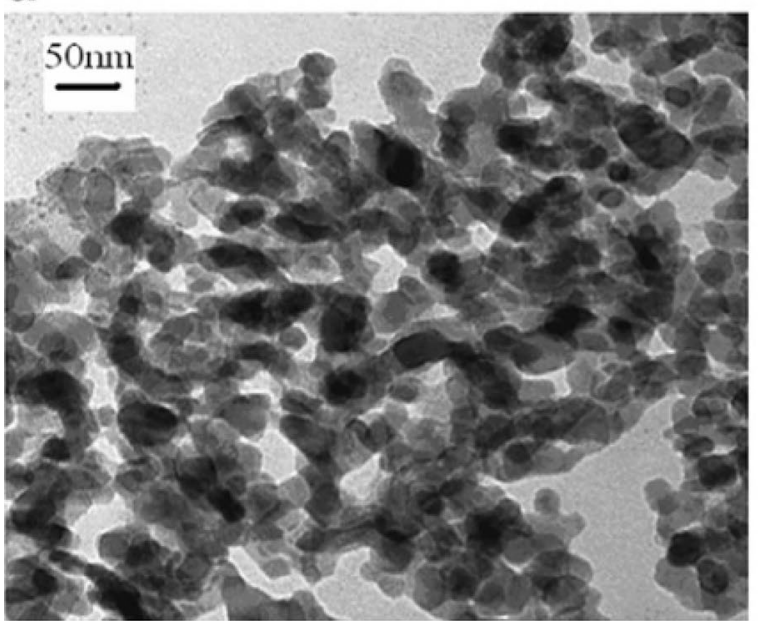

is higher if the absolute value of zeta potential is higher [37]. Nanofluid with lower pH shows higher zeta potential [37]. Stability of nanofluid is determined comparing the data showed in Table 2. The value of zeta potential is a function of $\mathrm{pH}$. Hence, zeta potential of a nanofluid is different at different pH value. Sardarabadi et al. [38] evaluated the stability of K-CNT and Na-CNT nanofluid by measuring zeta potential.

\subsection{Electron microscopy method}

Most of the researchers now adopt electron microscopy method in addition with other method. This method needs sophisticated equipment called Transmission Electron Microscopy (TEM) device which capture electron micrograph. The resolution of images captured by this device is high. There is a possibility of sedimentation if clusters of nanoparticles are detected in the image. Zhu et al. [28] evaluated the stability of Cu nanofluid by TEM. Jalal et al. [40] used the same method for evaluating the stability of $\mathrm{ZnO} /$ glycerol nanofluid. TEM of stable nanofluid are demonstrated in Fig. 3.

\section{Techniques of enhancing nanofluid stability}

Density of nanofluid over different time can be measured with three-digit accuracy by laboratory density and concentration measurement device such as digital density meter. A circulating fluid temperature bath is used to maintain and measure the density of the specimen of nanofluid at different temperatures. But calibration and a benchmark test are required before measuring the desired nanofluid. b

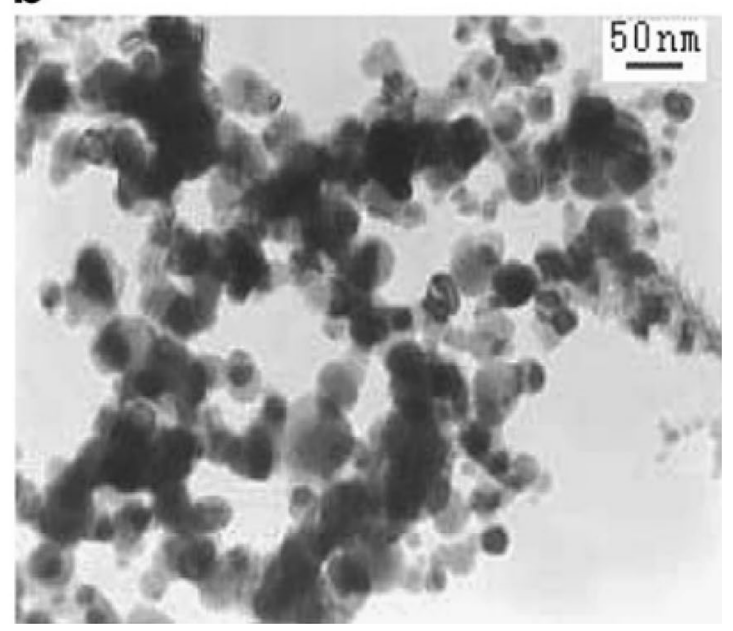

Fig. 3 TEM of a nano-alumina nanoparticles b nano-copper nanoparticles [41] 
Some researchers used Anton-Paar digital density meter to measure the density of different nanofluid $[42,43]$. Different methods have been developed in enhancing nanofluid stability. Addition of dispersant, and sonication are the notable methods. Addition of dispersant is the most economical method.

\subsection{Dispersant}

Addition of dispersants or surfactants is the common method in enhancing the stability of nanofluid which prevents the agglomeration of nanoparticles by reducing the surface tension of the base fluid. But excess use of dispersant may deteriorate the thermophysical properties of nanofluid including decrease in thermal conductivity as well as degradation of chemical stability [44]. Hence, dispersant should be used in optimum quantity. Surfactants chemically consists of two portions, hydrophilic polar head group and a long-chainhydrocarbons called hydrophobic tail. Some common dispersants are Sodium dodecyl benzene sulfonate (SDBS), Gum arabic, Sodium dodecyl sulphate (SDS), Polyvinylprolidone (PVP), Dodecyltrimethylammonium bromide (DTAB), Oleic Acid (OA), etc. Besides, surfactants like Disponil A 1580, Hypermer LP, Aerosol TR-70, Aerosol TR-70 HG, and Aerosol OT-70 PG are also used in particular case.

Jalal et al. [40] used ammonium citrate dispersant to enhance stability of $\mathrm{ZnO} / \mathrm{glycerol}$ nanofluid. SDBS dispersant was used to enhance stability of $\mathrm{Al}_{2} \mathrm{O}_{3}$ /water nanofluid by Zhu et al. [28]. 1-2.5 wt\% of Gum arabic (GA) was used by Rashmi et al. [45] as dispersant in enhancing the stability of carbon nanotubes (CNTs) nanofluids.

Asadi et al. [46] conduct an experimental investigation to study effect of surfactant on the stability of $\mathrm{Mg}(\mathrm{OH})_{2}$ / water nanofluid. SDS, Oleic Acid, and CTAB were used as surfactant. Sedimentation Photograph Method was used to observe the stability for 30 days and found that surfactant enhances the stability of $\mathrm{Mg}(\mathrm{OH})_{2}$ / water nanofluid. CTAB surfactants showed the best result among three surfactants. Visual sedimentation of this experiment is shown in Fig. 4.

\subsection{Magnetic stirring}

Magnetic stirrer is employed in laboratory which use rotating magnetic field to increase the homogeneity of nanofluid by reducing sediment. Generally, two knobs are present in a magnetic stirrer or magnetic mixer, left knob and right knob. Stirring rate is controlled by the left knob. On thee other hand, heating is controlled by the right knob. Magnetic stirring technique is used by some researcher before sonication [14, 47, 48]. Mansour et al. [49] used magnetic stirring to prepare $\mathrm{TiO}_{2}$ nanofluid.

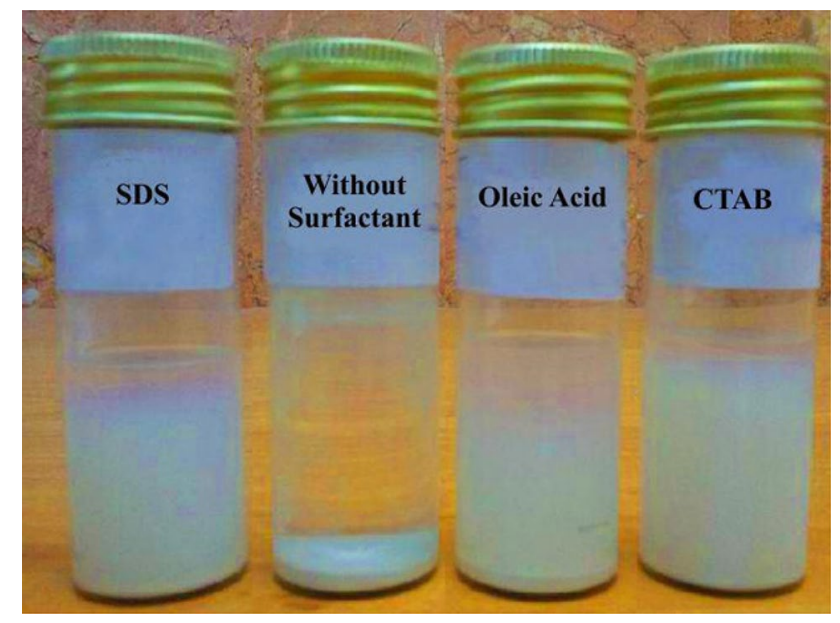

Fig. 4 Effect of surfactant on $\mathrm{Mg}(\mathrm{OH})_{2}$ / water nanofluid (after 30 days) [46]

\subsection{Sonication}

Sonication method gives better dispersion which has less probability of particle agglomeration than magnetic stirring. Ultrasonic waves are applied in sonication method through the nanofluid. Sonication helps to make more homogenized suspension. To provide uniform dispersion, sonication is better than magnetic stirrer. Two types of sonicates are available, bath type and probe type. Probe type sonication gives better performance than bath type sonication. The agglomerated nanoparticles are subjected to vibration by the ultrasonic waves when sonication is applied. The cavitation bubbles grow until critical state which are generated during sonication. The hot spots are created which are combination of very high local pressure and temperature. The hot-spots are generated during the critical state. The agglomerated particles are broken down by these hot spots $[37,50]$. The optimum sonication time is not still determined perfectly. Witharana et al. [51] sonicated $\mathrm{ZnO}, \mathrm{AL}_{2} \mathrm{O}_{3}, \mathrm{TiO}_{2}$ nanofluid for $16 \mathrm{~h}$. On the other hand, $\mathrm{TiO}_{2}$ nanofluid was sonicated in ultrasonic bath for two hours by Ghadim and Metselaar [52]. The optimum sonication time increases with the increase in volume fraction of nanofluid [37]. The stability of nanofluid decreases if sonication time exceeds optimum time $[37,46$, $50,53,54]$. The effect of sonication time for $\mathrm{Mg}(\mathrm{OH})_{2} /$ water nanofluid on the zeta potential is illustrated in Fig. 5.

\section{Heat transfer modeling of nanofluid}

Heat transfer modeling of nanofluid is important to understand the behavior of nanofluid. It is the prerequisite for the application of nanofluid. Currently there are different heat transfer modeling which are described below. 


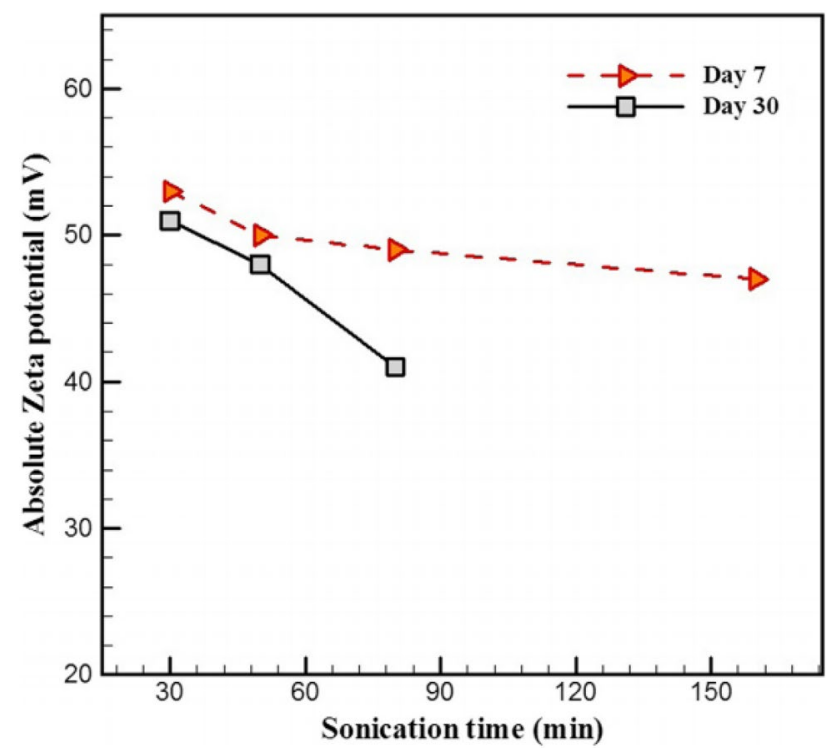

Fig. 5 Sonication time effect for $\mathrm{Mg}(\mathrm{OH})_{2}$ / water nanofluid on the Zeta Potential [46]

\subsection{Dispersion model}

Xuan and Roetzel [55] studied nanofluid by assuming that heat transfer in nanofluid depend on two factor which are higher thermal conductivity and stable dispersion of nanofluid. They also assumed that irregular movement of the nanoparticles induces small perturbations of both the temperature and velocity of the nanofluids. To handle the thermal dispersion, they proposed a dispersion model.

\subsection{Particle migration model}

Wen and Ding [56] adopted this model to develop a theoretical model in laminar pipe flow. This model considers shear-induced migration mechanism [57]. Another crucial two mechanism involves in this model which are migration because of induced viscosity gradient, and self-diffusion because of Brownian motion.

\subsection{Single-phase model}

In single-phase model, base fluid and nanoparticles are considered as one component. This model was first adopted by Choi [58]. In this model, traditional heat transfer equations are solved for nanofluid by changing thermophysical properties of nanofluids.

\subsection{Two-phase model}

In this model, the two components are fluid phase and nanoparticles and Brownian diffusion and thermophoresis are important slip. Both are accountable in heat transfer enhancement. Absolute velocity of nanoparticles is calculated from the sum of relative slip velocity and base fluid velocity. Buongiorno [59] included nanoparticle continuity equation which was coupled with the energy equation. Later, Rahman et al. [60] carried out investigation on this model.

\section{Thermophysical properties of nanofluid}

\subsection{Density of nanofluid}

Density of a substance is the ratio of mass to volume. The widely used equation to estimate density is the classical mixture law. By the classical mixture law, density of nanofluid can be expressed as,

$\rho_{n f}=\rho_{n p} \phi+(1-\phi) \rho_{b f}$

\subsection{Specific heat of nanofluid}

Specific heat of a substance is the amount of heat added or rejected to change the temperature by one degree. Calorimetry meter is used to measure the specific heat. Based on mixture law specific heat of nanofluids can be expressed as a function of the volume concentration and density of individual element using following equation [61].

$C_{p_{n f}}=C_{p_{n p}} \phi+(1-\phi) C_{p_{b f}}$

This equation is widely used in estimating specific heat of nanofluids. Assuming thermal equilibrium, Xuan and Roetzel [19] proposed specific heat of nanofluid as following equation which is widely used.

$C_{p_{n f}}=\frac{\phi \rho_{n p} C_{p_{n p}}+(1-\phi) \rho_{b f} C_{p_{b f}}}{\rho_{n f}}$

where

$\rho_{n f}=\rho_{n p} \phi+(1-\phi) \rho_{b f}$

Zhou et al. [62] showed that Eq. (3) give satisfactory result only at low concentrations. Hence, Eq. (5) is widely used in research of nanofluid for wide range of volume concentration.

\subsection{Thermal conductivity of nanofluid}

Maxwell [63] gave thermal conductivity model for solid-liquid mixtures based on Effective Medium Theory [EMT] which is applicable for spherical sized particles as 
the following equation. This thermal conductivity model is for solid-liquid mixtures of relatively large and low concentration particles.

$\frac{k_{n f}}{k_{b f}}=\frac{k_{p}+2 k_{b f}+2 \phi\left(k_{p}-k_{b f}\right)}{k_{p}+2 k_{b f}-\phi\left(k_{p}-k_{b f}\right)}$

Later, Hamilton-Crosser [64] proposed a model considering shape factor which is generalization of the Maxwell model as Eq. (7)

$\frac{k_{n f}}{k_{b f}}=\frac{k_{p}+(n-1) k_{b f}-(n-1) \phi\left(k_{b f}-k_{p}\right)}{k_{p}+(n-1) k_{b f}+\phi\left(k_{b f}-k_{p}\right)}$

where

$n=\frac{3}{\psi}$

$n=$ empirical shape factor, dimensionless, $\psi=$ sphericity, dimensionless, $\psi=1$ for spherical

Pak and Cho [61] gave the following formula for $\mathrm{Al}_{2} \mathrm{O}_{3}$ /Water nanofluid derived from classical model.

$\frac{k_{n f}}{k_{b f}}=1+7.47 \phi$

Li and Peterson [65] proposed a temperature dependent $\left(27^{\circ} \mathrm{C} \leq \mathrm{T} \leq 36^{\circ} \mathrm{C}\right)$ equation for $\mathrm{Al}_{2} \mathrm{O}_{3}$ /Water nanofluid as Eq. (10)

$\frac{k_{n f}}{k_{b f}}=1+0.764481 \phi+0.01868867 T-0.46214175$

Xuan et al. [66] gave a model considering Brownian motion as Eq. (11)

$\frac{k_{n f}}{k_{b f}}=\frac{K_{p}+2 K_{b f}-2\left(K_{b f}-K_{p}\right) \phi}{K_{p}+2 K_{b f}+\left(K_{b f}-K_{p}\right) \phi} k_{b f}+\frac{\rho_{p} \phi C_{p}}{2 k_{b f}} \sqrt{\frac{K_{B} T}{3 \pi r_{c} \mu}}$

Where

$K_{B}=$ Boltzmann constant,$\quad r_{c}=$ Apparent radius of clusters

Xue [67] devised a model for CNTs based nanofluid which is based on the Maxwell theory. The proposed model included space distribution as well as axial ratio.

$\frac{k_{n f}}{k_{b f}}=\frac{1-\phi+2 \phi \frac{k_{p}}{k_{p}-k_{b f}} \ln \frac{k_{p}+k_{b f}}{2 k_{b f}}}{1-\phi+2 \phi \frac{k_{b f}}{k_{p}-k_{b f}} \ln \frac{k_{p}+k_{b f}}{2 k_{b f}}}$

Yang et al. [68] proposed a model considering Brownian convection in the nanofluid as Eq. (13). The model was devised from kinetic theory of the nanoparticles. $\frac{k_{n f}}{k_{b f}}=\left[\frac{k_{p}+2 k_{b f}+2\left(k_{p}-k_{b f}\right) \phi}{k_{p}+2 k_{b f}-2\left(k_{p}-k_{b f}\right) \phi}\right] k_{b f}+157.5 \phi C_{f} u_{p}^{2} \tau$

where $C_{f}=$ Heat capacity of the fluid per unit volume, $u_{p}=$ Brownian velocity of the nanoparticles, $\tau=$ Relaxation time

\subsection{Dynamic viscosity of nanofluid}

When two adjacent fluid layers relatively moves each other, the resistance of fluid flow is expressed as dynamic viscosity which is the ratio of shear stress to the shear strain rate. Experimentally, dynamic viscosity can be measured through using viscometer. Einstein [69] equation is the prominent model in estimating dynamic viscosity which has the drawback of low volume concentration $(\phi \leq 0.02)$ and expressed as,

$\frac{\mu_{n f}}{\mu_{b f}}=1+2.5 \phi$

Brinkman [70] proposed a formula which is applicable up to volume concentration $4 \%$.

$\frac{\mu_{n f}}{\mu_{b f}}=\frac{1}{(1-\phi)^{2.5}}$

Abu-Nada [71] and Namburu et al. [72] investigated heat transfer enhancement of $\mathrm{Al}_{2} \mathrm{O}_{3} /$ Water and $\mathrm{Al}_{2} \mathrm{O}_{3} /$ EG (60\%)-W (40\%) nanofluid and proposed temperature-dependent model of Eqs. (16) and (17) for dynamic viscosity.

$$
\begin{aligned}
\mu_{n f}= & -0.155-\frac{19.582}{T}+0.794 \phi+\frac{2094.47}{T^{2}} \\
& -0.192 \phi^{2}-8.11 \frac{\phi}{T}-\frac{27463.863}{T^{3}} \\
& +0.127 \phi^{3}+1.6044 \frac{\phi^{2}}{T}+2.1754 \frac{\phi}{T^{2}}
\end{aligned}
$$

$\log \left(\mu_{n f}\right)=A e^{-B T}$

Where

$A=-0.29956 \phi^{3}+6.7388 \phi^{2}-55.44 \phi-236.11$

$B=\frac{\left(-6.4745 \phi^{3}+140.03 \phi^{2}-1478.5 \phi+20341\right.}{10^{6}}$

Equation (17) is applicable for temperature of $-35^{\circ} \mathrm{C} \leq T \leq 50^{\circ} \mathrm{C}$ and particle volume concentration of $1-10 \%$.

Batchelor [73] provided the following equation considering the Brownian motion of particles. 
$\frac{\mu_{n f}}{\mu_{b f}}=1+2.5 \phi+6.5 \phi^{2}$

Pak and Cho [61] studied $\mathrm{Al}_{2} \mathrm{O}_{3} /$ Water, $\mathrm{TiO}_{2} /$ Water nanofluid at room temperature and showed that Eq. (21) satisfy dynamic viscosity.

$\frac{\mu_{n f}}{\mu_{b f}}=1+39.11 \phi+533.9 \phi^{2}$

Nguyen et al. [74] proposed a temperature dependent model of Eq. (22) while Wang et al. [75] gave a model of Eq. (23) depending on particle concentration.

$\frac{\mu_{n f}}{\mu_{b f}}=\left(2.1275-0.0215 T+0.00027 T^{2}\right)$

$\frac{\mu_{n f}}{\mu_{b f}}=1+7.3 \phi+123 \phi^{2}$

Naddaf and Heris [76] investigated diesel oil based nanofluid and evaluated viscosity and density for a temperature range $5-100^{\circ} \mathrm{C}$. The investigation shows that viscosity and density of nanofluid decreases with the increase in temperature.

\section{Impact of different factors on thermal conductivity}

Thermal conductivity of nanofluid largely depends on the type of base fluid, type of nanoparticles, particle size, particle shape, and temperature.

\subsection{Base fluid}

Thermal conductivity of nanofluid depends on the thermal conductivity of the base fluid. Nanofluid possesses higher the thermal conductivity if the thermal conductivity of the base fluid is high.

\subsection{Nanoparticles}

Generally, metal oxides are used as the dispersed particles in the base fluid because of its chemical stability. In addition, pure metal is expensive. The thermal conductivity of nanofluid depends on the type of nanoparticles used in the base fluid. Nanoparticles are preferred which possesses high thermal conductivity.

\subsection{Nanoparticles concentration}

Thermal conductivity of nanofluid increases if the nanoparticle concentration increases [77-79]. Most of the effective thermal conductivity model provided by the researchers are based on the nanoparticle concentration. Both the linear and the non-linear relationship between thermal conductivity and nanoparticular concentration was established by researchers. Zhu et al. [77] found nonlinear relationship in case of $\mathrm{Fe}_{2} \mathrm{O}_{3}$ /water nanofluid. Barbés et al. [78] studied $\mathrm{CuO}$ nanofluid and found a linear relationship. A nonlinear increase in thermal conductivity of MWCNT nanofluid was found by Ding et al. [80]. Xie et al. [81] also found nonlinear relationship in case of glycol based CNT nanofluids.

\subsection{Particle size}

Nanofluid is prepared by nanoparticles with diameter of $1-100 \mathrm{~nm}$. Thermal conductivity of nanofluid also depends on the size of nanoparticles and has an inverse relationship [82]. The thermal conductivity of nanofluid get improved with the decreased nanoparticle size. If the particles are of small size, Brownian motion becomes prominent. Hence, chaotic movement increases in the base fluid. Hence, thermal conductivity of nanofluid get increased. The surface to volume ratio increases if the size of particle decreases [83]. Teng et al. [84] investigated the effect of $\mathrm{Al}_{2} \mathrm{O}_{3}$ nanoparticles size on the thermal conductivity of $\mathrm{Al}_{2} \mathrm{O}_{3}$ /water nanofluid. Enhancement of thermal conductivity was found in their investigation.

\subsection{Particle shape}

Hamilton-Crosser equation of thermal conductivity demonstrates that thermal conductivity also depends on the shape of nanoparticles. Shape of the particles may be different types like spherical, cylindrical or rod type, blade, brick type shapes and so forth. Effect of particle shape on $\mathrm{Al}_{2} \mathrm{O}_{3}$ /EG-water was investigated by Timofeeva et al. [85] and found that cylindrical shaped nanoparticles possesses highest thermal conductivity. Brick shaped nanoparticles possess higher thermal conductivity than platelet and blade shaped nanoparticle [86].

\subsection{Temperature}

Thermal conductivity of nanofluid is the temperature dependent property [87]. Researchers have found improved thermal conductivity of nanofluid with the increase in temperature. Brownian motion is liable because of this enhancement. Thermal conductivity increases with the increase in temperature as Brownian motion gets more vigorous. Das et al. [88] investigated $\mathrm{Al}_{2} \mathrm{O}_{3} /$ water and $\mathrm{CuO} /$ water nanofluid and found improved thermal conductivity with the increase in temperature. $\mathrm{Li}$ and Peterson [89] found the same result with $\mathrm{Al}_{2} \mathrm{O}_{3}$ /water nanofluid. 
Duangthongsuk and Wongwises [90] carried out experiment on $\mathrm{TiO}_{2} /$ water nanofluid with temperature between $15-30{ }^{\circ} \mathrm{C}$ and found increased in thermal conductivity. Naddaf and Heris [91] found increase in thermal conductivity with the increase in temperature for graphene/ DO and CNT/DO nanofluids.

\subsection{Surfactant}

Surfactants are used to enhance the stability of nanofluid by reducing agglomeration of nanoparticles. Surfactants reduce thermal conductivity of nanofluid, while improving stability. Khairul et al. researched $\mathrm{CuO} /$ water nanofluid with SDBS surfactant and discovered that thermal conductivity decreases after the addition of surfactant. Nanofluid thermal conductivity decreases with an increase in surfactant concentration [92]. Surfactant has lower thermal conductivity than the base fluid. As a result, effective thermal conductivity reduces. Therefore, surfactant should be used at optimum concentration.

\section{Heat transfer characteristics}

The heat transfer characteristics of nanofluid depends on different factors including thermophysical properties of base fluid and nanoparticles, nanoparticle concentration, nanoparticle size, presence of surfactants etc. Hence, functional form of Nusselt number of nanofluid can be expressed as [93],

$N u=f\left(\operatorname{Re}, \operatorname{Pr}, \frac{K_{p}}{K_{b f}}, \frac{\left(\rho C_{p}\right)_{p}}{\left(\rho C_{p}\right)_{b f}}, \phi\right.$, size of particle, shape of particle, flow structure $)$

$N u=c \operatorname{Re}_{b}^{m} \operatorname{Pr}^{0.4}$

Maiga et al. [97] proposed a correlation for Nusselt number of $\mathrm{Al}_{2} \mathrm{O}_{3}$ /water nanofluid as,

$N u=0.085 \operatorname{Re}^{0.71} \operatorname{Pr}^{0.35}$ for $6.6 \leq \operatorname{Pr} \leq 13.9 \& 10^{4} \leq \operatorname{Re} \leq 5 \times 10^{5}$

Yarmand et al. [98] numerically investigated $\mathrm{Al}_{2} \mathrm{O}_{3} /$ water nanofluid and compared the numerical result with Dittus-Boelter [99], Gnielinski [100], Pak and Cho [61], and
Heris et al. [94] numerically investigated $\mathrm{Al}_{2} \mathrm{O}_{3}$ /water nanofluid in a triangular duct and found that Nusselt number increases with the decrease in particle size and increase in volume fraction.

Pak and Cho [61] proposed a correlation of Eq. (25) for $\mathrm{Al}_{2} \mathrm{O}_{3} /$ Water, $\mathrm{TiO}_{2} /$ Water nanofluids in turbulent flow.

$N u=0.021 \operatorname{Re}^{0.8} \operatorname{Pr}^{0.5}$ for $6.54 \leq \operatorname{Pr} \leq 12.33 \& 10^{4} \leq \operatorname{Re} \leq 10^{5}$

Xuan and Li [95] studied CuO /Water nanofluid in turbulent flow and gave the correlation of Eq. (26). On the other hand, a new correlation of Eq. (27) for Nusselt number was given by Das et al. [96]

$N u=0.0059\left(1+7.6286 \phi_{p}^{0.6886} P e_{p}^{0.001}\right) \operatorname{Re}^{0.9238} \operatorname{Pr}^{0.4}$
Maiga [97]correlation. Figure 6 illustrates that the numerical result is the closest to Pak and Cho correlation.

\section{Applications of nanofluid}

\subsection{Heat exchanger}

Different types of heat exchanger including shell and tube, plate type, microchannel type, compact, and so forth are being widely used in the heavy industry, processing industry, etc. Recently, researchers are trying their utmost to increase the heat transfer performance of heat exchanger by substituting traditional heat transfer fluid with nanofluid [101]. MWNT/water nanofluid was investigated in shell and tube type heat exchanger by Lotfi et al. [102] and found incredible heat transfer enhancement because of the presence of multi-walled nanotube 
particles. Farajollahi et al. [103] investigated the effects of volume concentration of nanoparticles and Peclet number of $\mathrm{Al}_{2} \mathrm{O}_{3} /$ water and $\mathrm{TiO}_{2} /$ water nanofluids in shell and tube type heat exchanger. They found higher heat transfer coefficient in case of nanofluid. Pantzali et al. [104] performed experimental and CFD analysis of $\mathrm{CuO} /$ water nanofluid in plate heat exchanger. The investigation showed higher thermal conductivity of nanofluid. Asirvatham et al. [105] found $69.3 \%$ increase in heat transfer coefficient using silver nanofluid in double pipe heat exchanger because of the $0.9 \%$ volume fraction of nanoparticles. Besides, compact heat exchanger was investigated using nanofluid by Leong et al. [106], Huminic [107], and Vasu et al. [108] and found enhancement of heat transfer. Nanoparticles can be used for water desalination in solar heat exchanger. The rate of evaporation and condensation increases if nanoparticles are used in the solar system which is more cost effective [109]. Taghizadeh-Tabari et al. [110] investigated the performance of $\mathrm{TiO}_{2}$ nanofluid using plate heat exchanger for milk pasteurization industry. All volume fraction of $\mathrm{TiO}_{2}$ nanofluid showed higher heat transfer rate.

\subsection{Transportation cooling system}

Automotive and heavy-duty engines are associated with a plethora of heat. Engine may get damaged if this unwanted heat is not dissipated rapidly. The common coolant used in automotive cooling system is Ethelene glycol based HTF containing the volumetric ratio of EG to water of $60 / 40,50 / 50$. Ethelene glycol mixed with water increases the freezing temperature of pure water. More efficient and compact cooling system can be designed by using nanofluid. For the first time, Choi [5] suggested to use nanofluid in automotive cooling system. $\mathrm{Al}_{2} \mathrm{O}_{3} /$ water nanofluid enhances heat transfer up to $45 \%$ in the car radiator than pure water $[15,16]$. Heris et al. [111] found $55 \%$ enhancement of heat transfer coefficient in case of $\mathrm{CuO} / \mathrm{EG}$-water nanofluid compared with EG-water base fluid. Samira et al. [112] also investigated CuO/ EG-water nanofluid in car radiator and found that incorporation of nanoparticle increase heat transfer rate though pressure drop increases at the same time.

\subsection{Refrigeration}

The performance of CNT, gold and $\mathrm{HAuCl} 4$ nanoparticles suspended in Polyalkylene Glycol lubricant was investigated by Mohan et al. [113] in Vapour Compression Refrigeration System (VCRS). The outcome of their research was tremendous in the nanofluid research in refrigeration. Compression work reduces with the increase in volume fraction of nano-lubricant which enhance the COP. The COP increased by $31.7 \%$ with the incorporation of $0.1 \%$ gold with $0.005 \%$ CNT in Polyalkylene Glycol lubricant and exergy loss reduced by $8 \%$ at the same time. Wang et al. [114] investigated $\mathrm{R} 22$ refrigerant with $\mathrm{Al}_{2} \mathrm{O}_{3}$ nanoparticles and observed enhanced heat transfer characteristics. The height of boundary layer decreases because of the addition of nanoparticles in the refrigerant which enhances the flow boiling heat transfer [115]. Sheikholeslami et al. [116] carried an experimental investigation using $\mathrm{R} 600 \mathrm{a} / \mathrm{oil} / \mathrm{CuO}$ nano-refrigerant. Their investigation reveals that boiling heat transfer increases with the increase in nanoparticle's concentration.

\subsection{Electronics equipment}

In power generation industry, transformer cooling is important. Kulkarni et al. [117] applied $\mathrm{Al}_{2} \mathrm{O}_{3}$ nanofluid as jacket water coolant in a diesel electric generator to dissipated excess heat. Researchers are relentlessly giving their effort to reduce transformer size and weight by enhancing cooling system. Nanofluid can be a potential alternative by improving properties of conventional transformer oil [118]. Chips of electronic equipment produces much unnecessary heat which must be dissipated rapidly for the long lifespan of electronic equipment. Jang and Choi [119] recently designed a microchannel heat sink where nanofluid was used as HTF. Their investigation gave satisfactory result than pure water. Much electricity can be saved by improving efficiency of chiller with the help of nanofluid. Thermosyphon is now used for cooling the internal components of computer including processor. Researchers investigated different nanofluid in thermosyphon [120]. The heat transfer performance of thermosyphon largely depends on the thermal conductivity of the working fluid. If the thermal conductivity of working fluid of thermosyphon increases, the boiling heat transfer also increases in nucleate boiling regime [121]. Sardarabadi et al. [38] conducted an investigation of Na-MWCNT/water and KMWCNT/water nanofluid in TPCT for the purpose of electronic chip cooling. Na-MWCNT/water nanofluid showed higher thermal efficiency than K- MWCNT/water nanofluid.

\subsection{Transformer oil}

Transformer oil based nanofluids are promising because of higher thermophysical properties than conventional transformer oil. Carbon nanotubes (CNTs) have enhanced thermophysical properties than other materials [122-125] Beheshti et al. [126] investigated oxidized MWCNTs nanofluid based on transformer oil. The investigation shows that incorporation of oxidized MWCNT in transformer oil enhance both free and forced convective heat transfer rate. Also flash point increases by $4.6 \%$ because of 
the incorporation of 0.001 mass percentage of oxidized MWCNT nanoparticle.

\subsection{Industrial cooling}

Heavy duty machineries running all the day in the production of goods produce a large amount of unwanted heat which must be removed rapidly to avoid damage of the machineries. Nanofluids can be used as HTF in these machineries. Again, much energy can be saved in associated with nanofluid in industrial applications like cooling and heating of water resulting in less carbon dioxide emission to the environment [127]. About one trillion Btu energy can be saved by altering conventional HTF with nano fluid in USA [128].

\subsection{Cooling of nuclear system}

The power density is much high in the nuclear systems. Nanofluid has potential application as the main reactor coolant for Pressurized Water Reactors (PWR), Emergency Core Cooling Systems (ECCS), etc.[129].

\subsection{Machining operation}

Nanofluid demonstrates better result than conventional cutting fluid for machining operation which prevents the burning of the tool and workpiece [130, 131]. A large amount of heat generates during the grinding machining operation such as grinding, drilling, tapering etc. This excess heat must be dissipated rapidly in order to protect the work piece from phase transformation, thermal distortion, and residual stress. Crack may initiate, If the excess heat is not dissipated rapidly. The Critical Heat Flux (CHF) of coolant can be enhanced by substituting nano-coolant. Nano-coolants with high CHF protect from the thermal damage of the workpiece [130]. Salimi-Yasar et al. [131] used $\mathrm{TiO}_{2}$ / soluble oil nanofluid as cutting fluid during drilling and found that nanofluid causes less amortization and temperature of drilling.

\subsection{Geothermal energy extraction}

Geothermal energy is a renewable and sustainable energy resource. The estimated equivalent power of geothermal energy is 42 million MW which is expected to last for billion years. Nanofluid can extract more geothermal energy and can produce more power in Rankine cycle. The efficiency of the system can be increased by using nanofluid in geothermal boreholes and heat exchanger. Deneshipour and Rafee [132] carried an investigation of $\mathrm{Al}_{2} \mathrm{O}_{3}$ / water and $\mathrm{CuO} /$ water nanofluids as circuit fluid in geothermal borehole heat exchanger. The extracted heat by $\mathrm{CuO} /$ water nanofluid was higher than $\mathrm{Al}_{2} \mathrm{O}_{3}$ /water nanofluid. The extraction of heat increases with the increment of volume fraction.

\subsection{Solar energy and desalination}

There have been several investigations in the field of the solar collector based on nanofluid that demonstrate better result than the base fluid [133-136]. Saffariana et al. [137] found $78.25 \%$ increase in heat transfer by using $\mathrm{CuO} /$ water nanofluid in wavy pipes solar collector. Li et al. [138] used EG-based SiC-MWCNTs hybrid nanofluid in direct absorption solar collectors (DASC). Their investigation found $48.6 \%$ higher solar-thermal conversion efficiency than pure EG in DASC. Choudhary et al. [139] found an increased in thermal efficiency by $16.36 \%$ using $\mathrm{MgO}$ nanofluid than EG/DW in solar collector.

Many researchers carried out investigation on solar thermal desalination systems using nanofluids which give more potable drinking water by increasing efficiency [140, 141]. Parsa et al. [142] experimentally studied solar desalination system with silver nanofluid. Their study reveals that incorporation of silver nanoparticles increases the rate of heat transfer and at the same time, silver nanoparticles acts as anti-bacterial agent.

\subsection{Defence}

Most of military vehicles and equipment have heavy duty engines resulting production of much heat where high heat flux coolant is required. Defence equipment including submarine, fighter jet etc. must be compact with a good cooling system. Nanofluids have a great potential application in this equipment.

\section{Drawbacks of nanofluids}

- Sophisticated equipment is used to produce nanoparticles. Hence, production cost of nanofluid is high.

- Stability of nanofluid is poor without surfactant.

- Pressure drop and pumping power is increase with the increase in the density and viscosity of fluid. Density and viscosity of nanofluid is much higher than the base fluid. Hence pressure drop and pumping power of nanofluid is also higher than the base fluid.

- Specific heat of nanofluid is less than the base fluid. 


\section{Conclusions and future work}

The present study presents recent developments of nanofluid in heat transfer enhancement. The study extends to the preparation of nanofluid, stability of nanofluid, enhancing the stability of nanofluid, thermophysical properties, heat transfer characteristics, application. Nanofluid has some challenges for which further research should be conducted. Some probable studies that can be carried out in future research are listed below:

- Preparation of nanofluid is costly. Hence, efforts are required to identify cost-effective techniques for the nanofluid preparation.

- Stability is the main challenge of nanofluid which is crucial in the application as heat transfer fluid. More researches are required though some techniques are adopted in enhancing stability of nanofluid. The optimum time of sonication and magnetic stirring is not determined yet for different types of nanofluid. Moreover, optimum concentration of surfactant is not determined yet.

- The combination of different nanoparticles is not yet touched. Hence, effort can be made to find out the thermophysical properties of hybrid nanofluid.

- MWCNT demonstrates high thermal conductivity but very few studies have been carried out regarding the thermophysical properties and heat transfer characteristics of MWCNT. Research can be carried out for MWCNT nanofluid.

- Correlations for the thermophysical properties and heat transfer characteristics of different nanofluid are not yet been formulated. Researchers can carry out investigation in order to formulate new correlation of different nanofluid.

- There are many potential applications of nanofluid. Researchers have applied nanofluid in different fields such as heat exchanger, industrial cooling, automotive cooling system, nuclear systems, solar absorption, etc. More researches should be carried out before the application of nanofluid in nuclear system and some other fields.

\section{Compliance with ethical standards}

Conflict of interest The authors declare that they have no conflict of interest.

\section{References}

1. Lee S, Choi S, Li S, Eastman JA (1999) Measuring thermal conductivity of fluids containing oxide nanoparticles. J Heat Transfer 121:280-289

2. Eastman JA, Choi SUS, Li S et al (2001) Anomalously increased effective thermal conductivities of ethylene glycol-based nanofluids containing copper nanoparticles. Appl Phys Lett 78:718-720. https://doi.org/10.1063/1.1341218

3. Choi SUS, Zhang ZG, Yu W et al (2001) Anomalous thermal conductivity enhancement in nanotube suspensions. Appl Phys Lett 79:2252-2254. https://doi.org/10.1063/1.1408272

4. Das SK, Choi SU, Yu W, Pradeep T (2007) Nanofluids: science and technology. Wiley, NewYork

5. Choi S (2006) Nanofluids for improved efficiency in cooling systems. Heavy Veh Syst Rev 18-20

6. The Project. https://www.nanohex.org/the-project. Accessed 8 Aug 2020

7. Sarkar J (2011) A critical review on convective heat transfer correlations of nanofluids. Renew Sustain Energy Rev 15:3271-3277. https://doi.org/10.1016/j.rser.2011.04.025

8. Hwang Y, Park HS, Lee JK, Jung WH (2006) Thermal conductivity and lubrication characteristics of nanofluids. Curr Appl Phys 6:67-71

9. Lee SW, Park SD, Kang S et al (2011) Investigation of viscosity and thermal conductivity of $\mathrm{SiC}$ nanofluids for heat transfer applications. Int J Heat Mass Transf 54:433-438

10. Bobkov V, Fokin L, Petrov E et al (2018) Thermophysical properties of materials for nuclear engineering: a tutorial and collection of data. Int At Energy Agency, Vienna, Austria

11. Chung DDL (2001) Materials for thermal conduction. Appl Therm Eng 21:1593-1605

12. Hofmeister AM (2014) Thermal diffusivity and thermal conductivity of single-crystal $\mathrm{MgO}$ and $\mathrm{Al} 2 \mathrm{O} 3$ and related compounds as a function of temperature. Phys Chem Miner 41:361-371

13. Shackelford JF, Alexander W (2000) CRC materials science and engineering handbook, vol 3. CRC Press, Boca Raton

14. Kim SH, Choi SR, Kim D (2007) Thermal conductivity of metaloxide nanofluids: particle size dependence and effect of laser irradiation. J Heat Transfer 129:298-307

15. Peyghambarzadeh SM, Hashemabadi SH, Jamnani MS, Hoseini SM (2011) Improving the cooling performance of automobile radiator with $\mathrm{Al2O} /$ water nanofluid. J Appl Therm Eng 31:1833-1838

16. Nguyen CT, Roy G, Gauthier C, Galanis N (2007) Heat transfer enhancement using $\mathrm{Al} 2 \mathrm{O} 3$-water nanofluid for an electronic liquid cooling system. Appl Therm Eng 27:1501-1506

17. Hwang KS, Jang SP, Choi SUS (2009) Flow and convective heat transfer characteristics of water-based $\mathrm{Al} 2 \mathrm{O} 3$ nanofluids in fully developed laminar flow regime. Int J Heat Mass Transf 52:193-199

18. Chavda NK, Patel GV, Bhadauria MR, Makwana MN (2015) Effect of nanofluid on friction factor of pipe and pipe fittings: part ii effect of copper oxide nanofluid. Int J Res Eng Technol 4:697-700

19. Xuan Y, Roetzel W (2000) Conceptions for heat transfer correlation of Nanofluids. Int J Heat Mass Transf 43:3701-3708

20. Kakaç S, Pramuanjaroenkij A (2009) Review of convective heat transfer enhancement with nanofluids. Int J Heat Mass Transf 52:3187-3196

21. Sen Gupta S, Manoj Siva V, Krishnan S et al (2011) Thermal conductivity enhancement of nanofluids containing graphene nanosheets. J Appl Phys 110:084302 
22. Sheikholeslami M, Jafaryar M, Shafee A, Babazadeh H (2020) Acceleration of discharge process of clean energy storage unit with insertion of porous foam considering nanoparticle enhanced paraffin. J Clean Prod 261:121206. https://doi. org/10.1016/j.jclepro.2020.121206

23. Wen D, Lin G, Vafaei S, Zhang K (2009) Review of nanofluids for heat transfer applications. Particuology 7:141-150

24. Cheng L, Bandarra Filho EP, Thome JR (2008) Nanofluid twophase flow and thermal physics: a new research frontier of nanotechnology and its challenges. J Nanosci Nanotechnol 8:3315-3332. https://doi.org/10.1166/jnn.2008.413

25. Shanbedi M, Heris SZ, Amiri A et al (2015) Synthesis of aspartic acid-treated multi-walled carbon nanotubes based water coolant and experimental investigation of thermal and hydrodynamic properties in circular tube. Energy Convers Manag 105:1366-1376. https://doi.org/10.1016/j.encon man.2015.09.002

26. Heris SZ, Mohammadpur F, Mahian O, Sahin AZ (2015) Experimental study of two phase closed thermosyphon using cuo/ water nanofluid in the presence of electric field. Exp Heat Transf 28:328-343. https://doi.org/10.1080/08916152.2014.883448

27. Huminic G, Huminic A (2013) Numerical study on heat transfer characteristics of thermosyphon heat pipes using nanofluids. Energy Convers Manag 76:393-399. https://doi.org/10.1016/j. enconman.2013.07.026

28. Zhu HT, Lin YS, Yin YS (2004) A novel one-step chemical method for preparation of copper nanofluids. J Colloid Interface Sci 277:100-103

29. Zhu D, Li X, Wang N et al (2009) Dispersion behavior and thermal conductivity characteristics of $\mathrm{Al} 2 \mathrm{O} 3-\mathrm{H} 2 \mathrm{O}$ nanofluids. Curr Appl Phys 9:131-139

30. Sahooli M, Sabbaghi S (2012) CuO nanofluids: the synthesis and investigation of stability and thermal conductivity. J Nanofluids 1:155-160

31. Li X, Zhu D, Wang X (2007) Evaluation on dispersion behavior of the aqueous copper nano-suspensions. J Colloid Interface Sci 310:456-463

32. Nasser MS, James AE (2006) Settling and sediment bed behaviour of kaolinite in aqueous media. Sep Purif Technol 51:10-17. https://doi.org/10.1016/j.seppur.2005.12.017

33. Gharagozloo GE, Goodson KE (2010) Aggregate fractal dimensions and thermal conduction in nanofluids. J Appl Phys 108:074309. https://doi.org/10.1063/1.3481423

34. Mehrali M, Sadeghinezhad E, Rosen MA et al (2015) Heat transfer and entropy generation for laminar forced convection flow of graphene nanoplatelets nanofluids in a horizontal tube. Int Commun Heat Mass Transf 66:23-31

35. Singh AK, Raykar VS (2008) Microwave synthesis of silver nanofluids with polyvinylpyrrolidone (PVP) and their transport properties. Colloid Polym Sci 286:1667-1673

36. Fedele L, Colla L, Bobbo S et al (2011) Experimental stability analysis of different water-based nanofluids. Nanoscale Res Lett 6:300

37. Choudhary R, Khurana D, Kumar A, Subudhi S (2017) Stability analysis of $\mathrm{Al}_{2} \mathrm{O}_{3}$ /water nanofluids. J Exp Nanosci 12:140-151. https://doi.org/10.1080/17458080.2017.1285445

38. Sardarabadi H, Heris SZ, Ahmadpour A, Passandideh-Fard $M$ (2019) Experimental investigation of a novel type of twophase closed thermosyphon filled with functionalized carbon nanotubes/water nanofluids for electronic cooling application. Energy Convers Manag 188:321-332. https://doi.org/10.1016/j. enconman.2019.03.070

39. Chang H, Jwo CS, Fan PS, Pai SH (2007) Process optimization and material properties for nanofluid manufacturing. Int J Adv Manuf Technol 34:300-306
40. Jalal R, Goharshadi EK, Abareshi M et al (2010) ZnO nanofluids: green synthesis, characterization, and antibacterial activity. Mater Chem Phys 121:198-201

41. Wang XJ, Zhu DS (2009) Investigation of pH and SDBS on enhancement of thermal conductivity in nanofluids. Chem Phys Lett 470:107-111

42. Vajjha RS, Das DK, Mahagaonkar BM (2009) Density measurement of different nanofluids and their comparison with theory. Pet Sci Technol 27:612-624. https://doi. org/10.1080/10916460701857714

43. Akilu S, Baheta AT, Sharma KV (2020) Characterization and modelling of density, thermal conductivity, and viscosity of TiN-W/EG nanofluids. J Therm Anal Calorim 140:1999-2010. https://doi.org/10.1007/s10973-019-08902-5

44. Choi C, Yoo HS, Oh JM (2008) Preparation and heat transfer properties of nanoparticle-in-transformer oil dispersions as advanced energy-efficient coolants. Curr Appl Phys 8:710-712

45. Rashmi W, Ismail AF, Sopyan I et al (2011) Stability and thermal conductivity enhancement of carbon nanotube nanofluid using gum Arabic. J Exp Nanosci 6:567-579

46. Asadi $A$, Asadi M, Siahmargoi $M$ et al (2017) The effect of surfactant and sonication time on the stability and thermal conductivity of water-based nanofluid containing $\mathrm{Mg}(\mathrm{OH}) 2$ nanoparticles: an experimental investigation. Int J Heat Mass Transf 108:191-198. https://doi.org/10.1016/j.ijheatmasstrans fer.2016.12.022

47. Saleh R, Putra N, Wibowo RE et al (2014) Titanium dioxide nanofluids for heat transfer applications. Exp Therm Fluid Sci 52:19-29. https://doi.org/10.1016/j.expthermflusci.2013.08.018

48. Chakraborty S, Sarkar I, Behera DK et al (2017) Experimental investigation on the effect of dispersant addition on thermal and rheological characteristics of TiO2 nanofluid. Powder Technol 307:10-24. https://doi.org/10.1016/j.powtec.2016.11.016

49. Mansour DEA, Atiya EG, Khattab RM, Azmy AM (2012) Effect of titania nanoparticles on the dielectric properties of transformer oil-based nanofluids. In: Annual Report-Conference on Electrical Insulation and Dielectric Phenomena, CEIDP. IEE, pp 295-298

50. Afzal A, Nawfal I, Mahbubul IM, Kumbar SS (2019) An overview on the effect of ultrasonication duration on different properties of nanofluids. J Therm Anal Calorim 135:393-418. https://doi. org/10.1007/s10973-018-7144-8

51. Witharana S, Palabiyik I, Musina Z, Ding Y (2013) Stability of glycol nanofluids - the theory and experiment. Powder Technol 239:72-77

52. Ghadimi A, Metselaar IH (2013) The influence of surfactant and ultrasonic processing on improvement of stability, thermal conductivity and viscosity of titania nanofluid. Exp Therm Fluid Sci 51:1-9

53. Garg P, Alvarado JL, Marsh C et al (2009) An experimental study on the effect of ultrasonication on viscosity and heat transfer performance of multi-wall carbon nanotube-based aqueous nanofluids. Int J Heat Mass Transf 52:5090-5101. https://doi. org/10.1016/j.ijheatmasstransfer.2009.04.029

54. Sonawane SS, Khedkar RS, Wasewar KL (2015) Effect of sonication time on enhancement of effective thermal conductivity of nano TiO2-water, ethylene glycol, and paraffin oil nanofluids and models comparisons. J Exp Nanosci 10:310-322. https:// doi.org/10.1080/17458080.2013.832421

55. Xuan Y, Roetzel W (2000) Effect of particle migration on heat transfer in suspensions of nanoparticles flowing through minichannels. Int J Heat Mass Transf 43:3701-3708

56. Wen D, Ding Y (2005) Effect of particle migration on heat transfer in suspensions of nanoparticles flowing through minichannels. Microfluid Nanofluid 1:183-189 
57. Leighton D, Acrivos A (1987) The shear-induced migration of particles in concentrated suspensions. J Fluid Mech 181:415-439

58. Choi SUS, Eastman JA (1995) Enhancing thermal conductivity of fluids with nanoparticles. ANL/MSD/CP-84938; CONF951135-29 Argonne Natl Lab, (United States)

59. Buongiorno J (2006) Convective transport in nanofluids. J Heat Transfer 128:240-250

60. Rahman MM, Grosan T, Pop I (2016) Oblique stagnation-point flow of a nanofluid past a shrinking sheet. Int J Numer Methods Heat Fluid Flow 26:189-213

61. Pak BC, Cho Yl (1998) Hydrodynamic and heat transfer study of dispersed fluids with submicron metallic oxide particles. Exp Heat Transf an Int J 11:151-170

62. Zhou LP, Wang BX, Peng XF, Du XZ, Yang YP (2010) On the specific heat capacity of CuO nanofluid. Adv Mech Eng 2010:1-4

63. Maxwell JC (1973) A Treatise on electricity and magnetism. Clarendon press, UK Clarendon

64. Hamilton RL, Crosser OK (1962) Thermal conductivity of heterogeneous two-component systems. IEC Fundam 1:187-191

65. Li C, Peterson GP (2006) Experimental investigation of temperature and volume fraction variations on the effective thermal conductivity of nanoparticles suspensions (nanofluids). J Appl Phys 99:084314

66. Xuan Y, Li Q, Hu W (2003) Aggregation structure and thermal conductivity of nanofluids. AIChE J 49:1038-1043

67. Xue QZ (2005) Model for thermal conductivity of carbon nanotube-based composites. Phys B Condens Matter 368:302-307

68. Yang B (2008) Thermal conductivity equations based on Brownian motion in suspensions of nanoparticles (nanofluids). J Heat Transfer 130:042408

69. Einstein A (1906) A new determination of molecular dimensions. Ann Phys 19:289-306

70. Brinkman HC (1952) The viscosity of concentrated suspensions and solution. J Chem Phys 20:571-581

71. Abu-Nada E (2009) Effects of variable viscosity and thermal conductivity of Al2O3-water nanofluid on heat transfer enhancement in natural convection. Int J Heat Fluid Flow 30:679-690

72. Namburu PK, Das DK, Tanguturi KM, Vajjha RS (2009) Numerical study of turbulent flow and heat transfer characteristics of nanofluids considering variable properties. Int J Therm Sci 48:290-302

73. Batchelor GK (1977) The effect of Brownian motion on the bulk stress in a suspension of spherical particles. J Fluid Mech 83(1):97-117

74. Nguyen CT, Desgranges F, Roy G et al (2007) Temperature and particle-size dependent viscosity data for water-based nanofluids-hysteresis phenomenon. Int J Heat Fluid Flow 28:1492-1506

75. Wang X, Xu X, Choi SUS (1999) Thermal conductivity of nanoparticle-fluid mixture. J Thermophys heat Transf 13:474-480

76. Naddaf A, Heris SZ (2019) Density and rheological properties of different nanofluids based on diesel oil at different mass concentrations: an experimental study. J Therm Anal Calorim 135:1229-1242. https://doi.org/10.1007/s10973-018-7456-8

77. Zhu H, Zhang C, Liu S et al (2006) Effects of nanoparticle clustering and alignment on thermal conductivities of Fe 304 aqueous nanofluids. Appl Phys Lett 89:023123

78. Barbés B, Páramo R, Blanco E, Casanova C (2014) Thermal conductivity and specific heat capacity measurements of $\mathrm{CuO}$ nanofluids. J Therm Anal Calorim 115:1883-1891

79. Sundar LS, Hortiguela MJ, Singh MK, Sousa AC (2016) Thermal conductivity and viscosity of water based nanodiamond (ND) nanofluids: an experimental study. Int Commun Heat Mass Transf 76:245-255
80. Ding $Y$, Alias $H$, Wen D, Williams RA (2006) Heat transfer of aqueous suspensions of carbon nanotubes (CNT nanofluids). Int J Heat Mass Transf 49:240-250

81. Xie H, Chen L (2009) Adjustable thermal conductivity in carbon nanotube nanofluids. Phys Lett A 373:1861-1864

82. Akilu S, Sharma KV, Baheta AT, Mamat R (2016) A review of thermophysical properties of water based composite nanofluids. Renew Sustain Energy Rev 66:654-678. https://doi. org/10.1016/j.rser.2016.08.036

83. Kazemi-Beydokhti A, Heris SZ, Moghadam N et al (2014) Experimental investigation of parameters affecting nanofluid effective thermal conductivity. Chem Eng Commun 201:593611. https://doi.org/10.1080/00986445.2013.782291

84. Teng TP, Hung YH, Teng TC, Mo HE, Hsu HG (2010) The effect of alumina/water nanofluid particle size on thermal conductivity. Appl Therm Eng 30(14-15):2213-2218

85. Timofeeva EV, Routbort JL, Singh D (2009) Particle shape effects on thermophysical properties of alumina nanofluids. J Appl Phys 106:014304

86. Kim HJ, Lee SH, Lee JH, Jang SP (2015) Effect of particle shape on suspension stability and thermal conductivities of waterbased bohemite alumina nanofluids. Energy 90:1290-1297

87. Duangthongsuk W, Wongwises S (2009) Measurement of temperature-dependent thermal conductivity and viscosity of TiO2-water nanofluids. Exp Therm fluid Sci 33:706-714

88. Das SK, Putra N, Thiesen P, Roetzel W (2003) Temperature dependence of thermal conductivity enhancement for nanofluids. J Heat Transfer 125:567-574

89. Li CH, Peterson GP (2006) Experimental investigation of temperature and volume fraction variations on the effective thermal conductivity of nanoparticle suspensions (nanofluids). J Appl Phys 99:084314

90. Duangthongsuk W, Wongwises S (2010) An experimental study on the heat transfer performance and pressure drop of TiO2-water nanofluids flowing under a turbulent flow regime. Int J Heat Mass Transf 53:334-344

91. Naddaf A, Heris SZ (2018) Experimental study on thermal conductivity and electrical conductivity of diesel oil-based nanofluids of graphene nanoplatelets and carbon nanotubes. Int Commun Heat Mass Transf 95:116-122. https:// doi.org/10.1016/j.icheatmasstransfer.2018.05.004

92. Khairul MA, Shah K, Doroodchi E et al (2016) Effects of surfactant on stability and thermo-physical properties of metal oxide nanofluids. Int J Heat Mass Transf 98:778-787

93. Xuan Y, Roetzel W (2000) Conceptions for heat transfer correlation of nanofluids. Int J Heat Mass Transf 43:3701-3708

94. Heris SZ, Noie SH, Talaii E, Sargolzaei J (2011) Numerical investigation of al203/water nanofluid laminar convective heat transfer through triangular ducts. Nanoscale Res Lett 6:1-10. https://doi.org/10.1186/1556-276X-6-179

95. Xuan Y, Li Q (2003) Investigation on convective heat transfer and flow features of nanofluids. J Heat Transfer 125:151-155

96. Das SK, Putra N, Roetzel W (2003) Pool boiling characteristics of nano-fluids. Int J Heat Mass Transf 46:851-862

97. Maiga SB, Nguyen CT, Galanis N et al (2006) Heat transfer enhancement in turbulent tube flow using Al2O3 nanoparticle suspension. Int J Numer Methods Heat Fluid Flow 16:275-292

98. Yarmand H, Gharehkhani S, Kazi SN, Sadeghinezhad E, Safaei MR (2014) Numerical investigation of heat transfer enhancement in a rectangular heated pipe for turbulent nanofluid. Sci World J. https://doi.org/10.1155/2014/369593

99. Dittus FW (1930) Heat transfer in automobile radiators of the tubler type. Univ Calif Pubs Eng 2:443 
100. Gnielinski V (1976) New equations for heat and mass transfer in turbulent pipe flow and channel flow. Int Chem Eng 16:359-368

101. Sajid MU, Ali HM (2019) Recent advances in application of nanofluids in heat transfer devices: A critical review. Renew Sust Energy Rev 103:556-592. https://doi.org/10.1016/j. rser.2018.12.057

102. Lotfi R, Rashidi AM, Amrollahi A (2012) Experimental study on the heat transfer enhancement of MWNT-water nanofluid in a shell and tube heat exchanger. Int Commun Heat Mass Transf 39:108-111

103. Farajollahi B, Etemad SG, Hojjat M (2010) Heat transfer of nanofluids in a shell and tube heat exchanger. Int J Heat Mass Transf 53:12-17

104. Pantzali MN, Mouza AA, Paras SV (2009) Investigating the efficacy of nanofluids as coolants in plate heat exchangers (PHE). Chem Eng Sci 64:3290-3300

105. Asirvatham LG, Raja B, Lal DM, Wongwises S (2011) Convective heat transfer of nanofluids with correlations. Particuology 9:626-631

106. Leong KY, Saidur R, Mahlia TMI, Yau Y (2012) Modeling of shell and tube heat recovery exchanger operated with nanofluid based coolants. Int J Heat Mass Transf 55:808-816

107. Huminic G, Huminic A (2012) The cooling performances evaluation of nanofluids in a compact heat exchanger. SAE Tech Pap

108. Vasu V, Krishna KR, Kumar ACS (2008) Thermal design analysis of compact heat exchanger using nanofluids. Int J Nanomanuf 2:271-288

109. Seyednezhad M, Sheikholeslami M, Ali JA et al (2020) Nanoparticles for water desalination in solar heat exchanger. J Therm Anal Calorim 139:1619-1636. https://doi.org/10.1007/s1097 3-019-08634-6

110. Taghizadeh-Tabari Z, Zeinali HS, Moradi M, Kahani M (2016) The study on application of $\mathrm{TiO} 2 /$ water nanofluid in plate heat exchanger of milk pasteurization industries. Renew Sust Energy Rev 58:1318-1326. https://doi.org/10.1016/j.rser.2015.12.292

111. Heris SZ, Shokrgozar M, Poorpharhang S et al (2014) Experimental study of heat transfer of a car radiator with $\mathrm{CuO} / \mathrm{ethyl}-$ ene glycol-water as a coolant. J Dispers Sci Technol 35:677-684. https://doi.org/10.1080/01932691.2013.805301

112. Samira P, Saeed ZH, Motahare S (2014) Mostafa K (2014) Pressure drop and thermal performance of $\mathrm{CuO} /$ ethylene glycol (60\%)-water (40\%) nanofluid in car radiator. Korean J Chem Eng 324(32):609-616. https://doi.org/10.1007/S11814-014-0244-7

113. Mohan K, Sundararaj S, Gopi Kannan K, Kannan A (2020) Experimental analysis on refrigeration system using CNT, gold \& HAUCL4 nano fluids. Mater Today Proc. https://doi. org/10.1016/j.matpr.2020.04.156

114. Wang KJ, Ding GL, Jiang WT (2006) Nano-scale thermal transporting and its use in engineering. In: Proceedings of the 4th Symposium on Refrigeration and Air Conditioning. Southeast University Press, Nanjing, China, pp 66-75

115. Vassallo P, Kumar R, D'Amico S (2004) Pool boiling heat transfer experiments in silica-water nano-fluids. Int J Heat Mass Transf 47:407-411

116. Sheikholeslami M, Rezaeianjouybari B, Darzi M et al (2019) Application of nano-refrigerant for boiling heat transfer enhancement employing an experimental study. Int J Heat Mass Transf 141:974-980. https://doi.org/10.1016/j.ijheatmass transfer.2019.07.043

117. Kulkarni DP, Vajjha RS, Das DK, Oliva D (2008) Application of aluminum oxide nanofluids in diesel electric generator as jacket water coolant. Appl Therm Eng 28:1774-1781

118. Wang $X Q$, Mujumdar AS (2008) A review on nanofluidspart II: experiments and applications. Brazilian J Chem Eng 25:631-648

\section{SN Applied Sciences \\ A SPRINGER NATURE journal}

119. Jang SP, Choi SU (2006) Cooling performance of a microchannel heat sink with nanofluids. Appl Therm Eng 28:2457-2463

120. Buschmann MH (2013) Nanofluids in thermosyphons and heat pipes: Overview of recent experiments and modelling approaches. Int J Therm Sci 72:1-17. https://doi.org/10.1016/j. ijthermalsci.2013.04.024

121. Trisaksri V, Wongwises S (2007) Critical review of heat transfer characteristics of nanofluids. Renew Sust Energy Rev 11:512523. https://doi.org/10.1016/j.rser.2005.01.010

122. Li X, Chen W, Zou C (2020) The stability, viscosity and thermal conductivity of carbon nanotubes nanofluids with high particle concentration: A surface modification approach. Powder Technol 361:957-967. https://doi.org/10.1016/j.powtec.2019.10.106

123. Amiri A, Shanbedi $M$, Eshghi $\mathrm{H}$ et al (2012) Highly dispersed multiwalled carbon nanotubes decorated with Ag nanoparticles in water and experimental investigation of the thermophysical properties. J Phys Chem C 116:3369-3375. https://doi. org/10.1021/jp210484a

124. Xie H, Lee H, Youn W, Choi M (2003) Nanofluids containing multiwalled carbon nanotubes and their enhanced thermal conductivities. J Appl Phys 94:4967-4971. https://doi. org/10.1063/1.1613374

125. Shanbedi M, Heris SZ, Amiri A, Baniadam M (2014) Improvement in heat transfer of a two-phased closed thermosyphon using silver-decorated MWCNT/water. J Dispers Sci Technol 35:1086-1096. https://doi.org/10.1080/01932691.2013.833101

126. Beheshti A, Shanbedi M, Heris SZ (2014) Heat transfer and rheological properties of transformer oil-oxidized MWCNT nanofluid. J Therm Anal Calorim 118:1451-1460. https://doi. org/10.1007/s10973-014-4048-0

127. Routbort J (2009) Argonne national lab. Michellin North America: St. Gobain Corp. http://www1.eere.energy.gov/industry/ nanomanufacturing/pdfs/nanofluids_industrial_cooling.pdf

128. Wong KV, de Leon O (2010) Applications of nanofluids: current and future. Adv Mech Eng 2010:10

129. Buongiorno J, Hu LW, Kim SJ et al (2008) Nanofluids for enhanced economics and safety of nuclear reactors: an evaluation of the potential features, issues, and research gaps. Nucl Technol 162:80-91

130. Kim SJ, Bang IC, Buongiorno J, Hu LW (2007) Surface wettability change during pool boiling of nanofluids and its effect on critical heat flux. Int J Heat Mass Transf 50:4105-4116

131. Salimi-Yasar H, Heris SZ, Shanbedi M et al (2017) Experimental investigation of thermal properties of cutting fluid using soluble oil-based TiO2 nanofluid. Powder Technol 310:213-220. https://doi.org/10.1016/j.powtec.2016.12.078

132. Daneshipour M, Rafee $R$ (2017) Nanofluids as the circuit fluids of the geothermal borehole heat exchangers. Int Commun Heat Mass Transf 81:34-41. https://doi.org/10.1016/j.ichea tmasstransfer.2016.12.002

133. Sadeghi G, Nazari S, Ameri M, Shama F (2020) Energy and exergy evaluation of the evacuated tube solar collector using Cu2O/water nanofluid utilizing ANN methods. Sustain Energy Technol Assess 37:100578. https://doi.org/10.1016/j. seta.2019.100578

134. Dehaj MS, Mohiabadi MZ (2019) Experimental investigation of heat pipe solar collector using $\mathrm{MgO}$ nanofluids. Sol Energy Mater Sol Cells 191:91-99. https://doi.org/10.1016/j.solma t.2018.10.025

135. Sadeghzadeh $M$, Ahmadi MH, Kahani M et al (2019) Smart modeling by using artificial intelligent techniques on thermal performance of flat-plate solar collector using nanofluid. Energy Sci Eng 7:1649-1658. https://doi.org/10.1002/ese3.381

136. Tong $\mathrm{Y}$, Lee $\mathrm{H}$, Kang W, Cho H (2019) Energy and exergy comparison of a flat-plate solar collector using water, $\mathrm{Al} 2 \mathrm{O} 3$ nanofluid, 
and CuO nanofluid. Appl Therm Eng 159:113959. https://doi. org/10.1016/j.applthermaleng.2019.113959

137. Saffarian MR, Moravej M, Doranehgard MH (2020) Heat transfer enhancement in a flat plate solar collector with different flow path shapes using nanofluid. Renew Energy 146:2316-2329. https://doi.org/10.1016/j.renene.2019.08.081

138. Li X, Zeng G, Lei X (2020) The stability, optical properties and solar-thermal conversion performance of SiC-MWCNTs hybrid nanofluids for the direct absorption solar collector (DASC) application. Sol Energy Mater Sol Cells 206:110323. https:// doi.org/10.1016/j.solmat.2019.110323

139. Choudhary S, Sachdeva A, Kumar P (2020) Investigation of the stability of $\mathrm{MgO}$ nanofluid and its effect on the thermal performance of flat plate solar collector. Renew Energy 147:18011814. https://doi.org/10.1016/j.renene.2019.09.126

140. Garg K, Khullar V, Das SK, Tyagi H (2019) Parametric study of the energy efficiency of the $\mathrm{HDH}$ desalination unit integrated with nanofluid-based solar collector. J Therm Anal Calorim 135:1465-1478. https://doi.org/10.1007/s10973-018-7547-6

141. Shafieian A, Azhar MR, Khiadani M, Sen TK (2020) Performance improvement of thermal-driven membrane-based solar desalination systems using nanofluid in the feed stream. Sust Energy Technol Assess 39:100715. https://doi.org/10.1016/j. seta.2020.100715

142. Parsa SM, Rahbar A, Koleini MH et al (2020) A renewable energy-driven thermoelectric-utilized solar still with external condenser loaded by silver/nanofluid for simultaneously water disinfection and desalination. Desalination 480:114354. https ://doi.org/10.1016/j.desal.2020.114354

Publisher's Note Springer Nature remains neutral with regard to jurisdictional claims in published maps and institutional affiliations. 